\title{
Symptoms of PTSD among Children Living in War Zones in Same Cultural Context and Different Situations
}

\author{
Ahmed F. Fasfous, Isabel Peralta-Ramírez, \\ and Miguel Pérez-García \\ School of Psychology - University of Granada (Spain) \\ Centro de Investigación Mente, Cerebro y Comportamiento (CIMCYC). \\ University of Granada (UGR). Spain.
}

\begin{abstract}
Situations of war and military conflict have been linked to the development of Post-Traumatic Stress Disorder (PTSD). To our knowledge, there are no studies that have examined, within the same conflict and the same culture, exposure to different traumatic events or traumatic events of different intensity. The aim of this study was to evaluate the symptoms of PTSD among Palestinian schoolchildren in two different areas of Hebron. A total of 381 schoolchildren from different parts of Hebron participated in the study. To evaluate the symptoms of PTSD, the children were asked to complete the Child Post Traumatic Stress Reaction Index. To evaluate the traumatic events experienced, they completed the Gaza Traumatic Event Checklist. Results indicate that $77.4 \%$ of the children living in Hebron show symptoms of moderate-to-severe PTSD, and $20.5 \%$ of them meet the DSM-IV diagnostic criteria for chronic PTSD. There were no significant differences in total symptoms between the two areas of Hebron, but there were differences within the specific types of symptoms. It is clear that the traumatic events of the war lead to the development of post-traumatic stress in children and that psychological intervention is necessary.
\end{abstract}

Literature suggests that exposure to the traumatic events of war is related to high levels of PTSD among the victims of military conflicts. However, there are important differences between the stressors and prevalence of PTSD in each conflict due to cultural differences, type of conflict, and PTSD instruments ad- 
ministrated. Therefore, this study will compare Palestinian children from the same city, subjugated to the same conflict, and raised in the same culture; however the sample draws from two different types of stressful contexts.

In this regard, studies conducted in war zones indicate that exposure to the traumatic event leads to the development of PTSD in childhood and adulthood (Attari, Dashty, \& Mahmoodi, 2006; Elbert et al., 2009; Carlson \& RosserHogan, 1994; Nader, Pynoos, Fairbanks, Al-Ajeel, \& Al-Asfour, 1993; Qouta, Punamaki, \& El Sarraj, 2003; Thabet \& Vostanis, 2000). Different studies have been performed to determine the incidence of PTSD resulting from exposure to traumatic events. Studies from different conflicts have produced results that range from a high incidence to low incidence of children with PTSD who had been exposed to war and conflicts. A study carried out on Kuwaiti children who had lived through the Gulf war found that $70 \%$ of children showed symptoms of PTSD ranging from moderate to severe (Nader et al., 1993). A later study involving a sample of Iranian children who had witnessed a public hanging next to their school in Isfahan found that $75 \%$ reported a tendency for moderate-to-severe symptoms of PTSD (Attari et al., 2006).

In one study conducted in Palestine, $41 \%$ of the children of Gaza revealed a tendency to show moderate-to-severe PTSD symptoms (Thabet \& Vostanis, 2000). A different study showed that the incidence of post-traumatic stress in 121 Palestinian children exposed to bombings was twice as high as results found in the previous study; 87\% exhibited moderate to severe PTSD (Qouta et al., 2003). All of these studies found a high incidence of PTSD in children exposed to situations of war and conflict. However, other studies have found lower incidence rates. For example, a study conducted in Lebanon found that only $20 \%$ of Lebanese children who had been exposed to bombings and terrorist attacks met the diagnostic criteria for PTSD (Saigh, 1991). In addition, a study conducted in Sri Lanka following two decades of war and unrest found that $25 \%$ of the country's children met the diagnostic criteria for PTSD.

With regard to gender differences in the development of PTSD after living through situations of conflict or war, most studies find that girls show more symptoms of the disorder than boys (Durakovic-Belko, Kulenovic, \& Dapic, 2003; Macksoud \& Aber, 1996; Miller El-Masri, Allodi, \& Qouta, 1999). However, Khamis (2005) conducted a study in Palestine and found that boys displayed more PTSD symptoms than girls. Contrary to both, a study performed in Palestine by Elbedour, Onwuegbuzie, Ghannamc, Whitcome, and Abu Hein (2007) found no significant differences between the two sexes.

These studies, however, did not give consideration to important variables that could explain their differing findings. For example, some studies evaluated PTSD after the conflict had ended (Awadah, Vance, El-Beblawi, \& Pumariega, 1998), or they compared very different conflicts (De Jong et al., 2001). For these reasons, we decided to study PTSD in children who are subject to stress 
situations of the same conflict and in the same cultural and socio-demographic context.

The conflict in Palestine is still underway. For over six decades, the Palestinian population has lived through different types of traumatic events (e.g., killings, arrests, and destruction of homes and agricultural land). The city of Hebron is recognized in Palestine for its atypical circumstances: it is the largest city in the West Bank (a Palestinian territory) and a group of Israeli settlers currently live in the historic center of the city (Palestinian Central Bureau of Statistics, 2009). After the signing of the 1997 Hebron Agreement by the Israeli government and the Palestinian National Authority, the city was divided into two areas. The area called $\mathrm{H} 1$ ( $80 \%$ of the city) is under Palestinian control and is inhabited by over 115,000 Palestinians. The area called $\mathrm{H} 2$ has a population of over 35,000 Palestinians and about 500 Israeli settlers. This part of the city, according to the Hebron Agreement, is to be under Israeli military control, although its administration is the responsibility of the Palestinian authority. During the Second Intifada (2000) the Israeli army took control of $\mathrm{H} 1$ for several months (B'tselem, 2003). At the time of this study, H1 was under Palestinian control, although the Israeli army made incursions into the area.

Children, as part of the Palestinian population of Hebron, are an especially vulnerable group. They experience a variety of violent attacks in their daily lives. It is therefore necessary that studies be conducted to illustrate the traumas that boys and girls living in the city may experience, as well as the posttraumatic symptoms they may display as a result. Thus far, few studies have focused on PTSD among the Palestinian children of this region. One of the most important studies focused on Palestinian schoolchildren of the West Bank and found that $34.1 \%$ of them suffered from PTSD. Most of these children were older, employed male refugees (Khamis, 2005). Other studies revealed high rates of PTSD in primary school-aged children who had experienced the war firsthand. Of the sample, $39 \%$ showed symptoms ranging from moderate to severe (Thabet \& Vostanis, 1999).

To our knowledge, no previous studies have considered differences in type of stressor or symptoms in different Palestinian territories. The aim of this study is to evaluate the impact of different traumatic events and the psychological consequences of their aftermath for children living in conflict zones, such as Hebron. It is important to note that this study allows variables such as culture and type of conflict to be controlled, as it compares two situations of exposure to traumatic events ( $\mathrm{H} 1$ and $\mathrm{H} 2)$ in the same city and with the same population. Also, as secondary objectives, (1) the prevalence of the PTSD will be studied, (2) if differences between girls and boys in the type of stressors and symptoms exist, and, finally, (3) if a positive relation between the number of stressors and symptoms exist. We hypothesized that type of stressor and symptoms will be different for $\mathrm{H} 1$ and $\mathrm{H} 2$, that the prevalence of PTSD will 
be similar to previously reported, that girls will experience more PTSD symptoms and, finally, that the more traumatic events children experience, the more symptoms children suffer.

\section{Methods}

\section{Target Population}

According to the Ministry of Education in the city of Hebron, there are 4,241 13 -year-olds attending 59 schools. In H1, under Palestinian authority, there are 34 schools ( 16 for boys and 18 for girls) which have 2,732 (1,463 boys and 1,269 girls) 7 th grade students. In H1, under Israeli control (with the presence of some Israeli settlers in addition to the Palestinian population), there are 25 schools ( 12 for boys and 13 for girls) which have 1,509 (671 boys and 838 girls) 7 th grade students.

\section{Participants}

A total of 381 thirteen-year-old students (190 boys and 191 girls) participated in this study. This sample was divided into two groups, depending on where the students live in the city. The first group has 232 students (121 boys and 111 girls) who attend four schools located in H1. The second group has 149 students (69 boys and 80 girls) who attend five schools located in H2. In this study, the two different groups are equal in father's employment status $(10 \%$ of the children's fathers $(\mathrm{n}=15)$ in $\mathrm{H} 2$ area were unemployed, while in $\mathrm{H} 1$ area $7 \%$ of children's fathers $(n=16)$ were unemployed). This data was collected in a questionnaire that included questions about socioeconomic status.

\section{Measures}

Child Post Traumatic Stress Reaction Index (CPTSD-RI: Frederick, 1985):

The CPTSD-RI is a 20-item self-report questionnaire designed to assess PTSD reactions following exposure to a wide range of events in children and adolescents, ages 6 to 16 years old. The index includes three subscales: intrusion (seven items), avoidance (five items), and arousal (five items), along with three additional items (Thabet, Abed, \& Vostanis, 2002).

The responses are presented in a Likert-type 5-point rating scale (0-4). Based upon score ranges, the questionnaire classifies the degree of reaction as follows: scores of 0-11 = doubtful; $12-24=$ mild; $25-39=$ moderate; $40-59$ = severe; and above 60 = very severe (Frederick, 1985). Some previous studies 
suggest that a score of 40 or more is closely related to the diagnosis of PostTraumatic Stress (Pynoos et al., 1993). The inter-rater reliability of this instrument is high and its Cohen's kappa is 0.87 (Pynoos et al., 1987). This instrument has also shown high test-retest reliability (Goenjian et al., 1995). The CPTSD-RI has been translated to Arabic and validated for this culture (Thabet \& Vostanis, 1999).

Gaza Traumatic Event Checklist (Abu Hein, Qouta, Thabet, \& El Sarraj, 1993):

This checklist of items covers different types of traumatic events that a child may have experienced during his or her lifetime. The version used for this study is a subsequent 20 -item version that describes the most common traumatic experiences in the Gaza strip. The scale has been validated and deemed reliable for the Palestinian population (Thabet, Abed, \& Vostanis, 2004). This instrument uses a dichotomous response format (Thabet \& Vostanis, 1999).

\section{Procedure}

After the research project was planned, we requested permission from the Palestinian Ministry of Education to conduct the study. The Ministry provided information regarding the number of schools and their geographical distribution. The next step was to select the sample randomly, using the SPSS program. Then we went to the schools where the random sample of students attended to obtain the directors' permission to begin assessing the participants.

In most cases, the tests were administered early in the morning and in classrooms with teachers who facilitated the activity. All of the subjects participated in the study on a voluntary basis. Classroom presentations about objectives and process of this study were given to children by researcher. Then they invite children to participate in this study. However, children were chosen randomly using the SPSS program.

Variables and statistical analyses

\section{Variables}

The independent variables are gender (male and female) and place ( $\mathrm{H} 1$ and $\mathrm{H} 2$ ), both with two levels.

To study the relationship between the number of stressful events and the number of symptoms, a quartile variable was generated for traumatic events, with four levels: Q1 (1-2), Q2 (3-4), Q3 (5-6-7), Q4 (8-20).

The dependent variables were the scores obtained in the different rating scales administered. The total score of traumatic events included in the Gaza 
Traumatic Event Checklist equals the sum of the scoring for each event, which was coded " 1 " if the event occurred and " 0 " if it did not occur. The total score of symptoms included in the CPTSD-RI equals the sum of the scoring for each item, which was coded "0" for "never" and up to " 4 " for "always".

\section{Statistical analyses}

Analysis has been described according to each objective and following the same order. Also, as indicated before, objectives have been more clarified and ordered. In the results section, titles have been changed to be closer related with the objectives description and the order to show them has been matched to objectives. All results were processed in an SPSS database (version 15.0). To address the objective of studying differences in stressors and symptoms in two different contexts (H1 vs. H2; objective 1), a Student's t-test was used. To know what stressors and symptoms are associated with $\mathrm{H} 1$ or $\mathrm{H} 2$, an analysis of contingency tables was performed. In the case of the symptoms questionnaire, the responses to each item were classified into three categories, to avoid infrequent responses: Never $=$ Never; Sometimes and Not Very Often $=$ Sometimes; Almost Always and Always $=$ Almost Always .

To know the prevalence of PTSD in the sample (objective 2), number of children scoring more than 40 in the CPTSD-RI were obtained.

Also, to determine if there were differences between girls and boys in the two areas of Hebron (objective 3), both in terms of the total number of traumatic events and in total number of symptoms, four t-tests were performed, with the independent variables "gender in $\mathrm{H} 1$ " (boys in $\mathrm{H} 1$ vs. girls in $\mathrm{H} 1$ ), "gender in H2" (boys in $\mathrm{H} 2$ vs. girls in $\mathrm{H} 2$ ), "boys in both areas" (boys in $\mathrm{H} 1$ vs. boys in $\mathrm{H} 2$ ) and "girls in both areas" (girls in $\mathrm{H} 1$ vs. girls in $\mathrm{H} 2$ ). To know what stressors and symptoms are associated with gender, an analysis of contingency tables was performed.

We decided to do a quartile approach of number of stressors to obtain two things: to provide clinical information about what symptoms could you expect in children who suffer certain numbers of stressors and, 2) to not categorize the number of stressors in a subjective way. We add this rationality in the paper.

Finally, to study the relationship between traumatic events and symptoms and provide more clinical information about what symptoms you could expect in children who suffer a certain number of stressors, we obtained four groups from the total of traumatic events variable using the quartile score in order to avoid a subjective categorization of the variable.

Differences between those four groups in total of symptom variable were studied using an ANOVA. Due to the number of statistical analysis performed, the significant level was set at 0.01 to reduce the likelihood of type I error. 


\section{Results}

As a result of not completing the two main tests of this study, data for 8 children were missing in the Gaza traumatic events, while data for other 14 children were missing in the CPTSD-IR. In our study the mean number of traumatic events experienced by children in Hebron is 6.03. The intensity of these traumatic events occurred varies: $9.4 \%$ of the children have seen their homes destroyed and $94.8 \%$ of the children have seen images of dead and injured people on television.

A descriptive analysis was conducted to study how many participants showed symptoms of PTSD, in accordance with the cut-off points proposed by the author. Of the total, $1.8 \%(n=7)$ showed no symptoms, $16.5 \%(n=63)$ displayed mild PTSD, 47\% $(n=179)$ displayed moderate PTSD, 30.4\% $(n=116)$ displayed severe PTSD and $0.5 \%(n=2)$ suffered from very severe PTSD. The mean total of symptoms shown was 34.18 ( DT= 11.24). According to the three scales of the CPTSD-RI, 20.5\% of the sample meets the DSM-IV diagnostic criteria for PTSD (APA, 1994).

\section{Gender}

First, we studied the differences between boys and girls in the amount and type of traumatic events. We found statistically significant differences between boys and girls $[\mathrm{t}(1,360)=5.286 ; p<0.000]$, with the boys' total $(M=7.10 ; S D=4.22)$ being higher than the girls' total of traumatic events $(M=.4 .96 ; S D: 3.57)$.

Also, we found differences in the type of traumatic event experienced by children using a cross-tab analysis (gender $\mathrm{x}$ items). The results indicate that there are seven items of traumatic events that boys have suffered most frequently. The most important ones are: seeing a friend get hit by a bullet (item 7) $\left[\chi^{2}=27.0 ; p<0.000\right]$; being hit (item 8$)\left[\chi^{2}=22.3 ; p<0.000\right]$; seeing friend be arrested by soldiers (item 13) $\left[\chi^{2}=14.3\right.$; $\left.\mathrm{p}<0.000\right]$; or seeing soldiers burst into your home at night (item 12) $\left[\chi^{2}=13 ; \mathrm{p}<0.000\right]$ (see Table 1).

With regard to the symptoms of PTSD, no significant differences in the total were found, but it is more frequent for the girls to relive the images repeatedly (almost always $>42.9 \%$ ) $\left[\chi^{2}=13.8 ; p<0.001\right]$, and to be upset by reminders (almost always $>52.4 \%)\left[\chi^{2}=12.0 ; p<0.002\right]$.

Place (H1 vs. H2)

Considering the place variable, no significant differences were found between the two areas in the total of traumatic events. There were differences, however, within the type of traumatic event experienced. The results show that it is more frequent for the people of $\mathrm{H} 1$ to find about the death of a friend at the hands 
TABLE 1. The percentage of occurrence and $\chi^{2}$ of each traumatic event by gender.

\begin{tabular}{lccccc}
\hline & \multicolumn{3}{c}{ Boys } & Girls & \\
THE TRAUMATIC EVENT & \% Yes & \% Yes & \% Yes & $\chi^{2}$ & $P$ \\
\hline 1. Seeing images of dead and injured people on TV & 94.8 & 94.7 & 94.8 & 0.00 & 0.990 \\
2. Seeing aerial bombings against houses and streets & 80.3 & 86.3 & 74.7 & 8.12 & $\mathbf{0 . 0 0 4}$ \\
3. Finding out about the death of a friend at the hands & & & & & \\
$\quad$ of the Israeli army & 24.1 & 29.6 & 18.9 & 5.88 & 0.015 \\
4. Waiting for many hours at the checkpoints & 47.0 & 52.1 & 42.3 & 3.63 & 0.057 \\
5. Finding out that a father, a sibling, or other close & & & & & \\
$\quad$ family member has been killed by the & & & & & \\
$\quad$ occupying forces & 29.1 & 31.7 & 26.7 & 1.17 & 0.280 \\
6. Witnessing the destruction of a friend's home & 22.8 & 27.9 & 17.9 & 5.38 & 0.020 \\
7. Seeing a friend get hit by a bullet & 23.9 & 35.3 & 12.6 & 27.0 & $\mathbf{0 . 0 0 0}$ \\
8. Seeing a friend being hit by soldiers & 37.8 & 47.9 & 27.7 & 16.4 & $\mathbf{0 . 0 0 0}$ \\
9. Seeing a father, a sibling, or other family member & & & & & \\
$\quad$ killed by soldiers & 11.8 & 15.3 & 8.4 & 4.26 & 0.039 \\
10. Being hit or humiliated by soldiers & 31.0 & 42.3 & 19.9 & 22.3 & $\mathbf{0 . 0 0 0}$ \\
11. Seeing soldiers break into your home during & & & & & \\
$\quad$ the day & 28.9 & 31.7 & 26.2 & 1.43 & 0.231 \\
12. Seeing soldiers break into your home at night & 32.5 & 41.5 & 24.1 & 13.0 & $\mathbf{0 . 0 0 0}$ \\
13. Seeing a friend arrested by soldiers & 31.5 & 40.5 & 22.5 & 14.3 & $\mathbf{0 . 0 0 0}$ \\
14. Seeing a parent or a sibling get hit by a bullet & 12.6 & 15.3 & 9.9 & 2.44 & 0.118 \\
15. Seeing your home being bombed by artillery and & & & & & \\
$\quad$ heavy weaponry & 14.7 & 18.9 & 10.5 & 5.46 & 0.019 \\
16. Witnessing the attack of nearby homes by bombs, & & & & & \\
$\quad$ artillery, or heavy weaponry & 25.7 & 31.6 & 20.0 & 6.66 & $\mathbf{0 . 0 1 0}$ \\
17. Seeing a parent or a sibling being arrested & & & & & \\
$\quad$ by soldiers & 18.1 & 22.1 & 14.2 & 3.98 & 0.046 \\
18. Seeing a parent or a sibling being hit by soldiers & 17.8 & 21.1 & 14.7 & 2.66 & 0.103 \\
19. Being injured by a (rubber) bullet & 10.0 & 11.1 & 8.9 & 0.47 & 0.494 \\
20. Witnessing the destruction of your home & 9.4 & 13.2 & 5.8 & 6.09 & 0.014 \\
\hline
\end{tabular}

*The mean is not included because it is the same as the percentage of Yes responses

of the Israeli army (item 3) and to witness the attack of nearby houses with bombs, artillery, or heavy weaponry (item 16) than for the people of H2. On the other hand, it is more frequent for the people of $\mathrm{H} 2$ to have to wait for many hours at checkpoints (item 4), to see friends being hit (item 8) or arrested (item 13), to be hit themselves (item 10), and to see soldiers break into their homes during the day (item 11) or at night (item 12; see Table 2).

While there were no significant differences between the two areas in the total of symptoms, there were significant results within the types of symptoms. Children of $\mathrm{H} 2$ showed more frequency in being easily startled (almost always $>36.9)\left[\chi^{2}=17.4 ; p<0.000\right]$, and to have a higher likelihood of memory problems (almost always $>40.9)\left[\chi^{2}=11.19 ; p<0.004\right]$. On the other hand, the 
TABLE 2. The percentage of occurrence and $\chi^{2}$ of each traumatic event by area.

\begin{tabular}{|c|c|c|c|c|c|}
\hline THE TRAUMATIC EVENT & $\%$ Yes & $\begin{array}{c}\mathrm{H} 1 \\
\% \text { Yes }\end{array}$ & $\begin{array}{l}\mathrm{H} 2 \\
\% \text { Yes }\end{array}$ & $\chi^{2}$ & $P$ \\
\hline 1. Seeing images of dead and injured people on TV & 94.8 & 93.5 & 96.6 & 1.76 & 0.184 \\
\hline 2. Seeing aerial bombings against houses and streets & 80.3 & 83.5 & 75.8 & 3.43 & 0.064 \\
\hline 3. Finding out about the death of a friend at the hands & 241 & 309 & 141 & 1384 & 0000 \\
\hline 4. Waiting for many hours at the checkpoints & 47.0 & 41.3 & 56.4 & 8.24 & 0.004 \\
\hline $\begin{array}{l}\text { 5. Finding out that a father, a sibling, or other close } \\
\text { family member has been killed by the }\end{array}$ & & & & & \\
\hline occupying forces & 29.1 & 30.7 & 26.8 & 0.66 & 0.416 \\
\hline 6. Witnessing the destruction of a friend's home & 22.8 & 21.2 & 25.5 & 0.95 & 0.331 \\
\hline 7. Seeing a friend get hit by a bullet & 23.9 & 22.4 & 26.2 & 0.71 & 0.401 \\
\hline 8. Seeing a friend being hit by soldiers & 37.8 & 26.7 & 55.0 & 30.9 & 0.000 \\
\hline 9. Seeing a father, a sibling, or other family member & & & & & \\
\hline killed by soldiers & 11.8 & 13.4 & 9.4 & 1.41 & 0.236 \\
\hline 10. Being hit or humiliated by soldiers & 31.0 & 24.7 & 40.9 & 11.2 & 0.001 \\
\hline 11. Seeing soldiers break into your home during the day & 28.9 & 22.5 & 38.9 & 11.9 & 0.001 \\
\hline 12. Seeing soldiers break into your home at night & 32.5 & 26.8 & 41.9 & 9.28 & 0.002 \\
\hline 13. Seeing a friend arrested by soldiers & 31.5 & 25.9 & 40.3 & 8.73 & 0.003 \\
\hline 14. Seeing a parent or a sibling get hit by a bullet & 12.6 & 14.2 & 10.1 & 1.42 & 0.233 \\
\hline $\begin{array}{l}\text { 15. See your home being bombed by artillery or } \\
\text { heavy weaponry }\end{array}$ & 14.7 & 14.2 & 15.4 & 0.11 & 0.744 \\
\hline $\begin{array}{l}\text { 16. Witnessing the attack of nearby homes by bombs, } \\
\text { artillery, or heavy weaponry }\end{array}$ & 25.7 & 29.4 & 20.1 & 4.10 & 0.043 \\
\hline $\begin{array}{l}\text { 17. Seeing a parent or a sibling being arrested } \\
\text { by soldiers }\end{array}$ & 18.1 & 19.0 & 16.8 & 0.31 & 0.575 \\
\hline 18. Seeing a parent or a sibling being hit by soldiers & 17.8 & 16.4 & 20.1 & 0.87 & 0.350 \\
\hline 19. Being injured by a (rubber) bullet & 10.0 & 10.8 & 8.7 & 0.44 & 0.506 \\
\hline 20. Witnessing the destruction of your home & 9.4 & 10.3 & 8.1 & 0.56 & 0.456 \\
\hline
\end{tabular}

Note: $\mathrm{H} 1=$ area 1 of Hebron; $\mathrm{H} 2$ = area 2 of Hebron.

*The mean is not included because it is the same as the percentage of Yes responses

people of $\mathrm{H} 1$ demonstrated a stronger sense of foreshadowing (almost always >29.8) $\left[\chi^{2}=9.32 ; p<0.009\right]$.

\section{Relationship between traumatic events and symptoms}

It was found that the number of traumatic events is related to the number of PTSD symptoms displayed. The results demonstrated that people who have experienced more traumatic events display more post-traumatic stress symptoms $(F(3,357)=11.53 ; p<0.000)$. (See figure 1$)$. Back analyses showed that there were statistically significant differences in the post-traumatic stress symptoms displayed by boys of quartile 1,2 , and 3 , and between quartile 2 and 4 . This data appeared with a clear linear tendency $(F(1,357)=34.41 ; p<0.000)$. 
Figure 1. Relationship between the mean number of symptoms and the number of traumatic events.

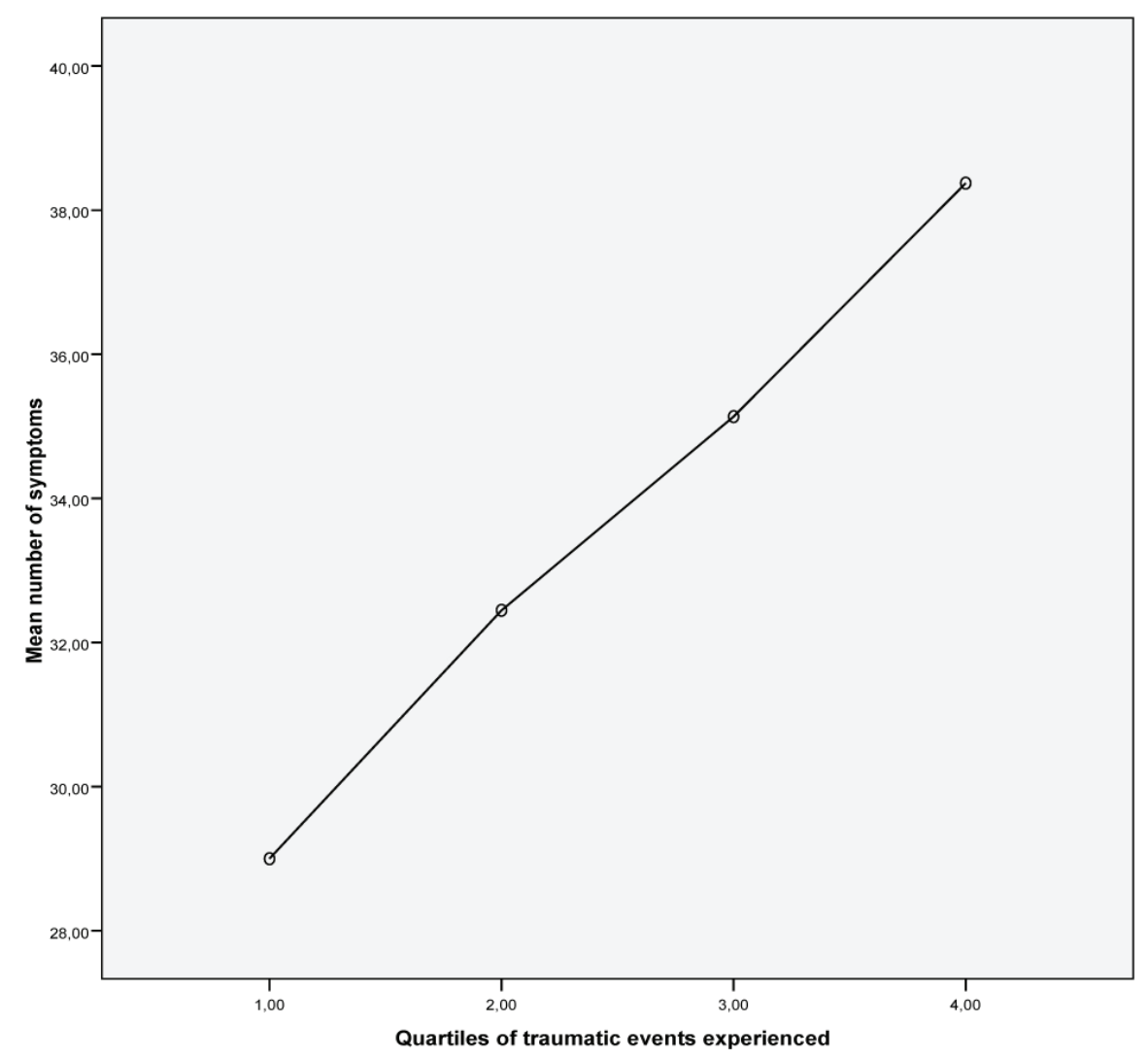

\section{Discussion}

The aim of this study was to compare two groups of Palestinian children, subjected to the same situation of decades-long conflict and who belong to the same cultural and socioeconomic context. Another goal was to compare these two groups based on different stressor contexts, areas $\mathrm{H} 1$ and $\mathrm{H} 2$ of Hebron. The findings reveal that the mean number of traumatic events experienced by the children of Hebron is 6.03. In addition, $77.4 \%$ of the children living in the city of Hebron who participated in this study showed symptoms of moderate or severe PTSD, and $20.5 \%$ of them meet the DSM-IV diagnostic criteria for PTSD (APA, 1994). Results also showed different types of PTSD stressors and symptoms depending on the area of Hebron where the children were living, and a positive direct relationship between the number of stressors and symptoms.

More specifically, no significant differences were found in the mean num- 
ber of traumatic events experienced by the people living in the two areas (H1 and $\mathrm{H} 2$ ). However, the type of traumatic events experienced did, in fact, differ. We found that events in $\mathrm{H} 1$ were more related to dangerous acts and death while events in $\mathrm{H} 2$ were more related to daily life. This may be due to the fact that the Second Intifada involved young Palestinians living in $\mathrm{H} 1$ and Israeli soldiers at the border of $\mathrm{H} 2$. Moreover, more infrastructures were bombed by Israeli troops in $\mathrm{H} 1$ during this Intifada. It is also important to note that the people of $\mathrm{H} 2$ must often wait for many hours at checkpoints because they are so plentiful in this area: two of the four schools included in the study (the AlIbrahimeyah Primary School for boys, and the Córdoba Primary School for girls) have electronic checkpoints on both sides of the building, and the other two (the Al-Hajereyeh Primary School for girls, and the Jawhar Primary School for boys) have regular checkpoints. Also, differences in the type of symptoms between $\mathrm{H} 1$ and $\mathrm{H} 2$ were found. Children under Israeli control experience more concrete and physiological symptoms such as being easily startled or memory problems. This could be explained because $\mathrm{H} 2$ children are exposed to more chronic stressors (such as crossing checkpoints several times a day). Chronic events have been shown to cause memory problems due to neural injury in the hippocampus (Astur et al., 2006)

Examining the development of PTSD by area, we found that H1 girls display more post-traumatic stress than $\mathrm{H} 1$ boys. In $\mathrm{H} 2$, however, girls did not experience more PTSD than boys. The results of $\mathrm{H} 2$ concur with studies carried out previously (Elbedour et al., 2007; Saigh, 1991; Thabet \& Vostanis, 1999). This could be explained by the typology of the traumatic events, since we find that when the events are chronic and frequent, no differences are detected between boys and girls. Specifically, in the case of $\mathrm{H} 2$, the stressors occur frequently (almost daily) and there are no discernible gender differences. In $\mathrm{H} 1$, on the other hand, the traumatic events are not as frequent and gender differences are more noticeable. These results could perhaps also be explained by the fact that at the time of the study, no Israeli military incursions into $\mathrm{H} 1$ had occurred, although the military remained present in $\mathrm{H} 2$.

It is likely that one of the factors contributing to differences in percentages in the development of post-traumatic stress is the duration of the stressor, since in stressful situations that continue over a long period of time, as in Palestine, studies tend to show high percentages of post-traumatic stress (BuydensBranchey, Noumair, \& Branchey, 1990; Kang, Natelson, Mahan, Lee, \& Murphy, 2003). However, in situations in which the stressful events are shorter-lived, the percentages fall. Another factor that must be taken into account is when the study took place, whether during a war or afterwards (Allwood, Bell-Dolan, \& Husain, 2002)

Studies that have looked into stressful events in conflict-ridden populations have continuously found varying percentages for the development of 
post-traumatic stress. In our case, the percentage is $77 \%$, one of the highest percentages. It coincides with the study by Thabet, Abed, and Vostanis (2004) involving Palestinian refugee children, and the study by Attari and colleagues (2006) involving Iranian children who had witnessed a public hanging. Other studies, however, have found lower percentages (Elbedour et al., 2007; Khamis, 2005; Saigh, 1991; Nader et al., 1993; Smith, Perrin, Yule, Hacam, \& Stuvland, 2002; Thabet \& Vostanis, 2000). It is likely that one of the factors contributing to differences in percentages in the development of post-traumatic stress is the duration of the stressor. Studies tend to show high percentages of posttraumatic stress in stressful situations that continue over a long period of time, as in Palestine. However, in situations where the stressful events are short-lived, the percentages tend to fall. Another factor that must be taken into account is when the study took place (e.g. during or after the war).

Among the most interesting results of this study is the finding that boys suffer more traumatic events than girls, which is similar to the findings of many previous studies (Husain et al., 1998; Khamis, 2005; Kuterovac, Dyregrov, \& Stuvland, 1994; Thabet \& Vostanis, 1999; Thabet, Abu Tawahina, El Sarraj, \& Vostanis, 2008). However, it contrasts with another study that found that boys and girls in Palestine experience the same number of traumatic events (Miller et al., 1999). In our study, girls do not experience traumatic events in greater proportion than boys, and they are equal to boys only in the situation of "seeing images of dead and injured people on TV". This difference between boys and girls in the number of experienced traumatic events could be a result of the socio-cultural factors. For example, girls in Hebron normally stay and play at home more than boys, who spend a portion of their time outside their home. Other reasons could be political; soldiers that are responsible for these events may focus their aggression towards boys more than girls. In fact, Children at this specific stage (13 years old) are entering the adolescence, and boys may be more likely than girls to participate in risky behavior, putting them at a higher risk of experiencing traumatic events.

In general terms, while the boys of our study experienced more traumatic events, it was the girls who exhibited more frequently to relive the images and to be upset by reminders. These findings coincide with other studies (Breslau, Davis, Andreski, \& Peterson, 1991; Kessler, 2000; Macksoud \& Aber, 1996; Qouta et al., 2003; Smith et al., 2002). Some studies, however, do not agree with this statement, finding instead that men display more symptoms of PTSD in conflict situations (Khamis, 2005). Gender differences in developing PTSD symptoms could be due to how males and females percept and interpret traumatic events. Girls may internalize the same traumatic event more deeply than boys, so their fear and reactions to such events might occur at a higher rate (Greenberg \& Schneider, 1995; Holbrook, Hoyt, Stein, \& Sieber, 2002). An- 
other reason could be the difference in cognitive processes between boys and girls (Simmons \& Granvold, 2005).

Our study has certain limitations. The uniform 13-year-old age of the sample limits the generalizability of our research. Given our results, it would perhaps have been interesting to take into consideration other psychological consequences of living through traumatic events, such as depression and behavior problems. Along these lines, it would have been interesting to examine the cognitive consequences and academic impact of PTSD symptoms. This topic should be addressed in future studies.

In short, it is clear that war and political violence has an effect on children at the psychological level. Our study has shown that boys and girls in $\mathrm{H} 1$ and $\mathrm{H} 2$ differ from each other in the type of stressors they experience and that both show a high rate of post-traumatic stress symptoms.

\section{References}

Abu Hein, F., Qouta, S., Thabet, A. A., \& El Sarraj, E. (1993). Trauma and mental health of children in Gaza. British Medical Journal, 306, 1130-1131. http://dx.doi. org/10.1136/bmj.306.6885.1130-c

Allwood, M. A., Bell-Dolan, D., \& Husain, S. A. (2002). Children's trauma and adjustment reactions to violent and nonviolent war experiences. Journal of the American Academy of Child and Adolescent Psychiatry, 41, 450-457. http://dx.doi. org/10.1097/00004583-200204000-00018

American Psychiatric Association. (1994). Diagnostic and statistical manual of mental disorders, DSM-IV, (4th ed., pp. 427-429). Washington DC, American Psychiatric Association.

Astur, R. S., St. Germain, S. A., Tolin, D., Ford, J., Russell, D., Stevens, M. (2006). Hippocampus function predicts severity of post-traumatic stress disorder. Cyberpsychology \& Behavior, 9, 234-240. http://dx.doi.org/10.1089/cpb.2006.9.234

Attari, A., Dashty, S., \& Mahmoodi, M. (2006). Post-traumatic stress disorder in children witnessing a public hanging in the Islamic Republic of Iran. Eastern Mediterranean Health Journal, 12, 72-80.

Awadh, A. M., Vance, B., El-Beblawi, V., \& Pumariega, A. J. (1998). Effects of trauma of the Gulf War on Kuwaiti children. Journal of Child and Family Studies 7, 493-498. http://dx.doi.org/10.1023/A:1022962127860

B'tselem, the Israeli Information Centre for Human Rights in the Occupied Territories. (Status Report August 2003). Hebron, Area H-2: Settlements Cause Mass Departure of Palestinians. Jerusalem.

Breslau, N., Davis, G. C., Andreski, P., \& Peterson, E. (1991). Traumatic events and posttraumatic stress disorder in an urban population of young adults. Archives of General Psychiatry, 48, 218-222. http://dx.doi.org/10.1001/archpsyc.1991.01810270028003

Buydens-Branchey, L., Noumair, D., Branchey, M. (1990). Duration and intensity of combat exposure and posttraumatic stress disorder in Vietnam veterans. Journal of Nervous and Mental Disease, 178, 582-587. http://dx.doi.org/10.1097/00005053199009000-00005 
Carlson, E. B., \& Rosser-Hogan, R. (1994). Cross-cultural response to trauma: A study of traumatic experiences and posttraumatic symptoms in Cambodian refugees. Journal of Traumatic Stress, 7, 43-58. http://dx.doi.org/10.1002/jts.2490070106

De Jong, J. T. V. M., Komproe, I. H., Van Ommeren, M., El Masri, M., Araya, M., Khaled, N., et al. (2001).?Lifetime events and posttraumatic stress disorder in 4 post conflict settings. Journal of the American Medical Association, 286, 555-562. http://dx.doi.org/10.1001/jama.286.5.555

Durakovic-Belko, E., Kulenovic, A., \& Dapic, R. (2003). Determinants of posttraumatic adjustment in adolescents from Sarajevo who experienced war. Journal of Clinical Psychology, 59, 27-40. http://dx.doi.org/10.1002/jclp.10115

Elbedour, S., Onwuegbuzie, A. J., Ghannam, J., Whitcome, J., \& Abu Hein, F. (2007). Post-traumatic stress disorder, depression, and anxiety among Gaza Strip adolescents in the wake of the second uprising (Intifada). Child Abuse \& Neglect, 31, 719-729. http://dx.doi.org/10.1016/j.chiabu.2005.09.006

Elbert, T., Schauer, M., Schauer, E., Huschka, B., Hirth, M., \& Neuner, F. (2009). Traumarelated impairment in children-A survey in Sri Lankan provinces affected by armed conflict. Child Abuse \& Neglect, 33, 238-246. http://dx.doi.org/10.1016/j. chiabu.2008.02.008

Frederick, C. J. (1985). Selected foci in the spectrum of post-traumatic stress disorders. In J. Laube \& S. A. Murphy (Eds.), Perspectives on disaster recovery (pp. 110-131). East Norwalk, CT: Appleton-Century-Crofts.

Goenjian, A. K., Pynoos, R. S., Steinberg, A. M., Najarian, L. M., Asarnow, J. R., Karayan, I., et al. (1995). Psychiatric comorbidity in children after the 1988 earthquake in Armenia. Journal of the American Academy of Child and Adolescent Psychiatry, 34, 1174-1184. http://dx.doi.org/10.1097/00004583-199509000-00015

Greenberg, M. R., \& Schneider, D. F. (1995). Gender differences in risk perception: Effects differ in stressed vs. nonstressed environments. Risk Analysis, 15, 503-511. http://dx.doi.org/10.1111/j.1539-6924.1995.tb00343.x

Holbrook, T. L., Hoyt, D. B., Stein, M. B., \& Sieber, W. J. (2002). Gender differences in long-term posttraumatic stress disorder outcomes after major trauma: Women are at higher risk of adverse outcomes than men.?Journal of Trauma, 53, 882-888. http://dx.doi.org/10.1097/00005373-200211000-00012

Husain, S. A., Nair, J., Holcomb, W., Reid, J. C., Vargas, V., \& Nair, S. S. (1998). Stress reactions of children and adolescents in war and siege conditions. American Journal of Psychiatry, 155, 1718-1719.

Kang, H. K., Natelson, B. H., Mahan, C. M., Lee, K. Y., Murphy, F. M. (2003). Posttraumatic stress disorder and chronic fatigue syndrome-like illness among Gulf War veterans: a population-based survey of 30,000 veterans. American Journal of Epidemiology. 157, 141 -148. http://dx.doi.org/10.1093/aje/kwf187

Kessler, R. C. (2000). Posttraumatic stress disorder: The burden to the individual and to society. Journal of Clinical Psychiatry, 61(5), 4-14.

Khamis, V. (2005). Post-traumatic stress disorder among school age Palestinian children. Child Abuse \& Neglect, 29, 81-95. http://dx.doi.org/10.1016/j.chiabu.2004.06.013

Kuterovac, G., Dyregrov, A., \& Stuvland, R. (1994). Children in war: A silent majority under stress. British Journal of Medical Psychology, 67, 363-375. http://dx.doi. org/10.1111/j.2044-8341.1994.tb01804.x

Macksoud, M. S., \& Aber, J. L. (1996). The war experiences and psychosocial development of children in Lebanon. Child Development, 67, 70-88. http://dx.doi. org/10.2307/1131687 
Miller, T., El-Masri, M., Allodi, F., \& Qouta, S. (1999). Emotional and behavioral problems and trauma exposure of school-age Palestinian children in Gaza: Some preliminary findings. Medicine, Conflict and Survival, 15, 368-378. http://dx.doi. org/10.1080/13623699908409478

Moisander, P. A., \& Edston, E. (2003). Torture and its sequel--a comparison between victims from six countries. Forensic Science International, 137, 133-140. http:// dx.doi.org/10.1016/j.forsciint.2003.07.008

Nader K. O., Pynoos R. S., Fairbanks L. A., Al-Ajeel, M., \& Al-Asfour, A. (1993). A preliminary study of PTSD and grief among the children of Kuwait following the Gulf crisis. British Journal of Clinical Psychology, 32, 407-416. http://dx.doi. org/10.1111/j.2044-8260.1993.tb01075.x

Palestinian Central Bureau of Statistics. (2009). Population, Housing, and Establishment Census 2007: Main Indicators by Locality Type. Palestine: Ramallah.

Pynoos, R. S., Frederick, C., Nader, K., Arroyo, W., Steinberg, A., Eth, S., et al. (1987). Life threat and posttraumatic stress in school-age children. Archives of General Psychiatry, 44, 1057-1063. http://dx.doi.org/10.1001/archpsyc.1987.01800240031005

Pynoos, R. S., Goenjian, A., Tashjian, M., Karakashian, M., Manjikian, A., Manoukian, G., et al. (1993). Post-traumatic stress reactions in children after the 1988 Armenian earthquake. British Journal of Psychiatry, 163, 239-247. http://dx.doi. org/10.1192/bjp.163.2.239

Qouta, S., Punamaki, R. L., \& El Sarraj, E. (2003). Prevalence and determinants of PTSD among Palestinian children exposed to military violence. European Child and Adolescent Psychiatry, 12, 265-272. http://dx.doi.org/10.1007/s00787-0030328-0

Saigh, P. A. (1991). The development of posttraumatic stress disorder following four different types of traumatization. Behavior Research and Therapy, 29, 213-216. http://dx.doi.org/10.1016/0005-7967(91)90110-O

Simmons, C.?A. \& Granvold, D.? K. (2005). A cognitive model to explain gender differences in rate of PTSD diagnosis.?Brief Treatment and Crisis Intervention, 5,?290299. http://dx.doi.org/10.1093/brief-treatment/mhi021

Smith, P., Perrin, S., Yule, W., Hacam, B., \& Stuvland, R. (2002). War exposure among children from Bosnia-Hercegovina: Psychological adjustment in a community sample. Journal of Traumatic Stress, 15, 147-156. http://dx.doi. org/10.1023/A:1014812209051

Thabet A. A., \& Vostanis, P. (2000). Post traumatic stress disorder reactions in children of war: A longitudinal study. Child Abuse \& Neglect, 24, 291-298. http://dx.doi. org/10.1016/S0145-2134(99)00127-1

Thabet, A. A., \& Vostanis, P. (1999). Posttraumatic stress reactions in children of war. Journal of Child Psychology \& Psychiatry, 40, 385-391. http://dx.doi. org/10.1111/1469-7610.00456

Thabet, A. A., Abed, Y., \& Vostanis, P. (2002). Emotional problems in Palestinian children living in a war zone: A cross-sectional study. Lancet, 359, 1801-1804. http:// dx.doi.org/10.1016/S0140-6736(02)08709-3

Thabet, A. A., Abed, Y., \& Vostanis, P. (2004). Comorbidity of PTSD and depression among refugee children during war conflict.?Journal of Child Psychology and Psychiatry, 45, 533-542. http://dx.doi.org/10.1111/j.1469-7610.2004.00243.x

Thabet, A. A., Abu Tawahina, A., El Sarraj, E., \& Vostanis, P. (2008)..European Child \& Adolescent Psychiatry,?17, 191-199. http://dx.doi.org/10.1007/s00787-007-0653-9 